\title{
Changes in Serine Metabolism by a Serum Factor Present in a Group of Episodic Psychotic Patients
}

\author{
D. Fekkes, L. Pepplinkhuizen, and J. Bruinvels
}

Addition of serum, obtained from patients suffering from an acute psychosis characterized by dysperceptions, to the culture media of fibroblasts altered the amino acid metabolism in these cells. After subculturing of fibroblasts in the presence of serum obtained from these patients, the concentrations of both serine and methionine were decreased in the medium as well as in the fibroblasts. Moreover, the concentration of taurine in the fibroblasts was increased. The specific activities of serine hydroxymethyltransferase and cystathionine $\beta$-synthase were also measured in the fibroblasts. It was found that both enzyme activities were significantly higher after subculturing with patients' serum as compared with serumobtained from healthy controls. It is concluded that a factor, present in the serum of these acute psychotic patients, is responsible for the observed changes in serine, taurine, and methionine concentrations in the fibroblasts as well as for the increased enzyme activities rentioned.

\section{Introduction}

Until now, no researchers have succeeded in ascribing the origin or existence of a psychosis to a general biochemical defect. A main reason for this failing is the fact that most psychiatrists look for biological correlates in heterogeneous groups of psychotic patients. Fortunately, we have concentrated on a rather homogeneous group of neuroleptic-resistant psychotic patients all suffering from dysperceptions (Pepplinkhuizen et al 1980; Bruinvels et al 1980). The psychosis is characterized by an acute onset with generalized sensory perceptual distortions of light, colors, taste, shape, distances, etc; after every psychotic episode all symptoms disappear. In addition to the characteristic perceptual symptoms, affective and so-called schizophrenic symptoms are present. According to DSM-III-R criteria (1987) these psychoses belong to the "psychotic disorders not elsewhene classified" (295.40, 295.70, and 298.80), as the criteria for a schizophrenic, affective, paranoid, or organic disorder were not met. Depending on the psychiatrist's country of origin, this acute psychosis has been preferentially diagnosed as degeneration, cycloid or atypical psychosis, or bouffée délirante (Bruinvels and Pepplinkhuizen 1985). This group of patients is resistant to treatment with neuroleptics, and complete recovery occurs after a diet rich in carbohydrates (398 $\mathrm{g} /$ day), low in fat ( $19 \mathrm{~g} /$ day), and minimal ( $60 \mathrm{~g} /$ day) protein.

By virtue of the findings described herein, a disturbed serine metabolism has been reported to be the basis of the psychotic episodes (Pepplinkhuizen et al 1980; Bruinvels

From the Biological Psychiatry Group, Departments of Pharmacology and Psychiatry, Medical Faculty, Erasmus University Rotterdam, The Netherlands.

Address reprint requests Dr. D. Fekkes, Section Pathophysiology of Behaviour, Medical Faculty, Erasmus University Rotterdam, P.O. Box 1738, 3000 DR Rotterdam, The Netherlands.

Received March 21, 1991; revised June 11, 1991. 
et al 1980). Recovered patients show, within a few hour after an oral administration of serine, psychedelic and psychotic symptoms, which are similar to those observed during the spontaneous psychosis of these prients. Amino acid analysis of fasting plasma samples of these serine-responsive patients indicate a decreased serine and an increased taurine concentration (Bruinvels et al 1984). Moreover, an impaired conversion of glycine into serine is found. Although the plasma data suggeš̀t an enzyme abnormality related to serine metabolism, up to now no enzymatic malfunctioning could be found in these patients (Fekkes and Bruinvels 1986). As these enzyme studies were performed in fibroblasts obtained from serine-responsive patients, the enzyme activities per se w'ere measured. Thus, the possibility that some factor circulating in these patients is responsible for the disturbed metabolism of serine cannot be ruled out.

It was, therefore, decided to mirror a more in vivo silluaition by subculturing fibroblasts, chtained from patients as well as norudi adivituals, in a medium supplemented with patients' serum or normal human serum, in order to detect aibations in amino acid concentrations in the culture medium and the cultured fibroblasts. Moreover, the specific activities of serine hydroxymethyltransferase (SHMT) and cystathionine $\beta$-synthase, both serine metabolizing enzymes, were measured in the fibroblasts.

\section{Methods}

The fibroblasts used in the present study, as well as the conditions used for normal growth, are the same as those described previously (Fekkes and Bruinvels 1986).

In short, fibroblasts obtained from both patients and controls were subcultured in medium (Ham's Fiô medium, supplemented with 4.5\% fetal calf serum, $4.5 \%$ newborn calf serum, $100 \mathrm{U}$ penicillin/ml, and $100 \mu \mathrm{g}$ streptomycin/ml), supplemented with $10 \%$ normal serum or $10 \%$ patients' serum. Normal serum was obtained from 8 healthy individuals and patients' serum was obtained from 8 episodic psychotic patients during an acute psychotic episode. In addition, serum obtained from 5 patients during a symptomfree period (clinically recovered patients) was tested. After 3 days of subculturing, most cell lines were grown to a near confluent state and the culture medium was withdrawn and used for amino acid analysis. Cells were washed two times in phosphate-buffered saline and harvested as described previously (Fekkes and Bruinvels 1986). The fibroblasts were used for amino acid analysis, protein determination, and for the measurement of the specific activities of SHMT, using serine as the substrate, and of cystathionine $\beta$ synthase. The enzyme assays, protein determination, and methods have been described previously (Fekkes and Bruinvels 1986). Amino acids were determined using a LKB amino acid analyzer (Bruinvels and Pepplinkhuizen 1984).

All experiments were done with primary cell lines obtained after 6-11 passages. In total, eight normal cell lines and eight patient cell lines were used throughout the study. Each time serum of a patient was compared with that of a healthy individual, two randomly chosen normal and patient cell lines were used. The concentrations of amino acids found in fibroblasts and media after subculturing the four different cell lines were averaged. Statistical analysis of data was carried out with the package of SPSS/PC + .

\section{Results}

The concentrations of the amino acid taurine in both the medium and the fibroblasts after subculiuring these cells with serum obtained from a normal individual or a patient are 
Table 1. Taurine Concentrations in the Medium and in the Fibroblasts after Subculturing Fibroblasts for 3 Days with Medium Supplemented with 10\% Normal (N) or $10 \%$ Patients' (P) Serum

\begin{tabular}{|c|c|c|c|c|c|c|}
\hline \multirow[b]{2}{*}{$\begin{array}{l}\text { Fibroolast } \\
\text { strain }\end{array}$} & \multicolumn{3}{|c|}{ Medium $(\boldsymbol{\mu} \mathbf{M})$} & \multicolumn{3}{|c|}{$\begin{array}{c}\text { Fibroblasts } \\
\text { (nmol/mg protein) }\end{array}$} \\
\hline & $\mathbf{N}$ & $\mathbf{P}$ & $\begin{array}{l}\mathbf{P} / \mathbf{N} \\
\text { ratio }\end{array}$ & $\mathbf{N}$ & $\mathbf{P}$ & $\begin{array}{l}\mathbf{P} / \mathbf{N} \\
\text { ratio }\end{array}$ \\
\hline No & 28.3 & 31.2 & 1.10 & 一 & 一 & - \\
\hline 82 RD 82 & 30.0 & 26.7 & 0.89 & 16.8 & 21.8 & 1.30 \\
\hline 82 RD 98 & 30.2 & 29.6 & 0.98 & 21.8 & 29.9 & 1.37 \\
\hline 82 RD 335 & 20.8 & 23.8 & 1.14 & 41.2 & 48.5 & 1.18 \\
\hline 83 RD 59 & 28.4 & 28.5 & 1.00 & 14.0 & 22.1 & 1.58 \\
\hline Mean & 27.3 & 27.0 & 1.00 & 23.5 & 30.6 & $1.36^{a}$ \\
\hline SEM & 2.2 & 1.3 & 0.05 & 6.1 & 6.3 & 0.08 \\
\hline
\end{tabular}

Fibroblast strains 82 RD 82 and 82 RD 98 were obtained from normal individuals, and strains 82 RD 335 and 83 RD 59 were obtained from serine-responsive psychotic patients.

${ }^{a}$ Significant difference was only found for the $\mathrm{P} / \mathrm{N}$ ratio in fibroblasts (two-tailed $\mathrm{t}$-test, $t=4.26, p<0.025$ ).

shown in Table 1. It can be seen that large variations in taurine concentrations are found, probably due to differences in growth rate of the fibroblast strains. Therefore, we determined the ratio ( $\mathrm{P} / \mathrm{N}$ ratio) of the amino acid concentrations measured after subculturing fibroblasts in the presence of $10 \%$ normal $(\mathrm{N})$ and $10 \%$ patients' $(\mathrm{P})$ serum. It can be seen clearly that the taurine concentrations are higher in the fibroblasts after subculturing these cells with patients' serum compared with normal serum, as reflected by a P/N ratio higher than $1.0(p<0.025)$. We have determined the $\mathrm{P} / \mathrm{N}$ ratio of several amino acids in the medium and in the fibroblasts of both controls and patients after subculturing these cells with medium supplemented with serum of 8 normal subjects and eight patients. The results of these experiments are shown in Table 2. The amino acids serine and methionine in both the medium and fibroblasts were significantly lower when subcultured with patients' serum than with normal serum, which is reflected by a P/N ratio lower than 1.0 .

Table 2. Amino Acid Ratios in the Medium and in the Fibroblasts after Subculturing Fibroblasts with Medium Supplemented with 10\% Serum of 8 Different Normais (N) or 10\% Serum of 8 Different Patients (P)

\begin{tabular}{lccc}
\hline & \multicolumn{2}{c}{ Medium $^{a}$} & Fibrablasts $^{a}$ \\
\cline { 2 - 4 } \multicolumn{1}{c}{$\begin{array}{c}\text { Amino } \\
\text { acid }\end{array}$} & $\begin{array}{c}\text { Before } \\
\text { subculturing }\end{array}$ & $\begin{array}{c}\text { After } 3 \text { days of } \\
\text { subculturing }\end{array}$ & $\begin{array}{c}\text { After } 3 \text { days of } \\
\text { subculturing }\end{array}$ \\
\hline Taurine & $1.13 \pm 0.06$ & $1.08 \pm 0.07$ & $1.31 \pm 0.05^{d}$ \\
Threonine & $1.01 \pm 0.02$ & $1.00 \pm 0.03$ & $0.97 \pm 0.02$ \\
Serine & $0.97 \pm 0.02$ & $0.89 \pm 0.03^{b}$ & $0.95 \pm 0.01^{\circ}$ \\
Glycine & $1.01 \pm 0.01$ & $1.02 \pm 0.02$ & $1.02 \pm 0.02$ \\
Alanine & $1.05 \pm 0.03$ & $1.04 \pm 0.02$ & $1.00 \pm 0.02$ \\
Methionine & $1.04 \pm 0.03$ & $0.94 \pm 0.02^{c}$ & $0.89 \pm 0.02^{d}$ \\
Leucine & $0.99 \pm 0.01$ & $0.98 \pm 0.02$ & $0.96 \pm 0.02$ \\
\hline
\end{tabular}

Regarding the fibroblaits, the P/N ratio at the start of the experiments was supposed to be 1.00 .

${ }^{a}$ Values represent means \pm SEM of the $P / N$ ratios.

Statistical significance of difference from the situation at the beginning of the experiment: ${ }^{b} p<0.05 ; \boldsymbol{p}<0.02:{ }^{d} p<$ $0.001 ;{ }^{e} p<0.002$ (two-tailed Student's $t$-test). 
Table 3. Amino Acid Ratios in the Medium and in the Fibroblasts after Subculturing Fibroblasts with Medium Supplemented with 10\% Serum of 5 Different Clinically Recovered Patients (PR) or 5 Different Normals $(\mathrm{N})$

\begin{tabular}{llclc}
\hline & \multicolumn{2}{c}{ Medium } & Fibroblasts \\
\cline { 2 - 3 } $\begin{array}{c}\text { Amino } \\
\text { Acid }\end{array}$ & $\begin{array}{c}\text { Before } \\
\text { subculturing }\end{array}$ & $\begin{array}{c}\text { After } \\
\text { subculuring }\end{array}$ & $\begin{array}{c}\text { After } \\
\text { subculturing }\end{array}$ \\
\hline Taurine & $1.14 \pm 0.06$ & $1.11 \pm 0.12$ & $1.16 \pm 0.08$ \\
Serine & $0.97 \pm 0.02$ & $0.99 \pm 0.01$ & & $1.02 \pm 0.02$ \\
Methionine & $1.02 \pm 0.03$ & $0.98 \pm 0.02$ & $0.99 \pm 0.01$ \\
\hline
\end{tabular}

Results are expressed as means \pm SEM of the PR/N ratros.

Moreover, a higher amount of taurine was formed in the cells after subculturing in the presence of patients' serum. All other amino acids, of which only a few are shown in Table 2, did not differ significantly between the patient and control groups. After all, no differences in ratios were found when fibroblasts from patients were used for the experiments compared to those from normals (not shown).

We wondered whether the metabolism of taurine, serine, and methionine would also be influenced when fibroblasts are subcultured with serum obtained from clinically recovered patients. In Table 3, the results are shown. It was found that the aforementioned amino acids in the medium, as well as in the fibroblasts, are not significantly different when subcultured with s:rum obtained from clinically recovered patients compared to normal serum. One-way analysis of variance was used to assess the significance of differences in amino acid ratios across all groups shown in Tables 2 and 3 . Homogeneity of variances was verified with Cochran's $C$-test. Significant differences between groups were found for serine $(F=5.877, p=0.0014)$ and for methionine $(F=7.482$, $p=0.0003)$. With the Student-Newman-Keuls multiple comparison procedure, pairs of groups were tested at the 0.05 level of significance for differences. Lower $\mathrm{P} / \mathrm{N}$ ratios were found for serine and methionine in the medium after 3 days of subculturing compared with ratios in the beginning of the experiment. The $P / N$ ratio for serine in the medium after 3 days of subculturing was also lower than the one in the fibroblasts. Moreover, the ratio for serine in the medium after 3 days of subculturing with patients' serum was lower compared with subculturing with serum of clinically recovered patients. For methionine, the ratio in the fibroblasts was lower when subcultured with patients' serum compared with serum from clinically recovered patients. For taurine, none of two groups were significantly different at the 0.05 level.

The specific activities of the enzymes SHMT and cystathionine $\beta$-synthase are shown in Table 4. It can be seen that both enzymes have higher activities after subculturing with patients' serum than with normal serum. However, in the presence of $1 \mathrm{mM}$ pyridoxal $5^{\prime}$-phosphate (pyridoxal- $P$ ), significance for SHMT was weak $(p=0.047)$. Because higher enzyme activities were expected when subcultured with patients' serum ( $\mathrm{P} / \mathrm{N}$ ratio for serine in the fibroblasts was lower than 1.0; see Table 2), a one-tailed $t$-test was used. Addition of pyridoxal-P increased SHMT activity by about $50 \%$, irrespective of subculturing with normal or patients' serum. The same holds for cystathionine $\beta$-synthase, although increment in activity for this enzyme was 30\%-40\%. Upon subculturing with serum obtained from recovered patients, both enzymes showed activities in the normal range (data not shown). 
Table 4. Specific Activities of SHMT and Cystathionine $\beta$-synthase in Fibroblasts after Subculturing in the Presence of $10 \% \mathrm{~N}$ or $10 \%$ P Serum

\begin{tabular}{|c|c|c|c|c|}
\hline \multirow[b]{2}{*}{ Addition } & \multicolumn{2}{|c|}{ SHMT $^{a}$} & \multicolumn{2}{|c|}{ Cystathionine $\beta$-synthase $^{a}$} \\
\hline & $\mathbf{N}$ & $\mathbf{P}$ & $\mathbf{N}$ & $\mathbf{P}$ \\
\hline None & $\begin{array}{c}3.22 \pm 0.15 \\
(6)\end{array}$ & $\begin{array}{c}3.89 \pm 0.11^{b} \\
(6)\end{array}$ & $\begin{array}{c}0.291 \pm 0.03 i \\
(8)\end{array}$ & $\begin{array}{c}0.413 \pm 0.054^{4} \\
\text { (6) }\end{array}$ \\
\hline $1 \mathrm{mM}$ pyridoxal-P & $\begin{array}{c}4.80 \pm 0.39 \\
(6)\end{array}$ & $\begin{array}{c}5.96 \pm 0.48^{c} \\
\text { (6) }\end{array}$ & $\begin{array}{c}0.377 \pm 0.015 \\
(8)\end{array}$ & $\begin{array}{c}0.577 \pm 0.039 \\
\text { (6) }\end{array}$ \\
\hline
\end{tabular}

\section{Discussion}

The findings of this study indicate that there is some factor present in the serum of episodic psychotic patients during acute psychoses that is responsible for the altered metabolism of serine, methionine, and taurine (Table 2). It was also found that this factor is not present or is inactive during periods when no psychotic symptoms are present (Table 3). The fact that the amounts of serine and methionine were lower in both the medium and the fibroblasts when subcultured with patients' serum, indicates that the serum factor alters the metabolism of these amino acids, and not the transport into the fibroblast. This also holds for taurine, which was higher in the fibroblasts after subculturing with patients' serum, whereas its concentration in the medium was unchanged. These results agree with the previously reported data concerning the plasma ccncentrations of serine and taurine (Bruinvels and Pepplinkhuizen 1984). However. the plasma level of methionine was lower, though not significantiy, whereas in this study we found that this amino acid was formed in significantly lower amounts in culture medium and fibroblasts in the presence of serum obtained from acute psychotic patients. A possible explanation for this difference may be the fact that human fibroblasts contain no betaine-homocysteine methyltransferase activity (Mudd et al 1970); therefore, regeneration of methionine via this pathway could not occur in fibroblasts. No significant differences could be found in the concentrations of other amino acids nor were there any differences between fibroblasts obtained from patients and normals with regard to the above-described altered metabolism of serine, taurine, and methionine.

The fact that the serine and methionine concentrations in the fibroblasts are lower when subcultured with patients' serum and the concentration of taurine is higher, suggests that the activity of cystathionine $\beta$-synthase and also of SHMT is increased by the serum factor (see Figure 1). Measurement of these enzymes in the fibroblasts showed that both have higher activities after subculturing with patients' serum (Table 4). Thus, an activation of these enzymes, due to some factor in the serum of these acute psychotic patients, exists. Again, in serum obtained from clinically recovered patients, this factor did not seem to be present, because no activation of these two enzymes was found when subculturing fibroblasts with serum obtained from these patients.

The percent increase in both enzyme activities after addition of $1 \mathrm{mM}$ pyridoxal-P was the same when subcultured with normal and patients' serum (49\% and $53 \%$ for SHMT, $30 \%$ and $40 \%$ for cysthationine $\beta$-synthase, respectively). This indicates that the 


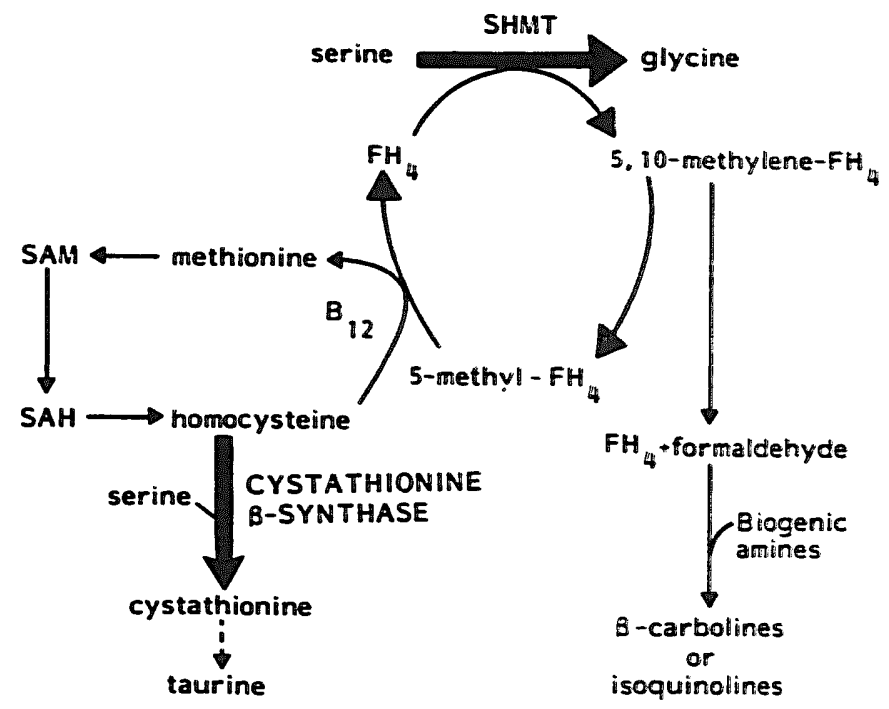

Figure 1. Pathways involved in the metabolism of serine. SHMT, serine hydroxymethyluransferase; $\mathrm{FH}_{4}$, tetrahydrofolic acid; SAH, $S$-adenosylhomocysteine; SAM, S-adenosylmethionine. Thick lines represent enzymatic steps that were found to be activated in the fibroblasts after incubation with serum obtained from episodic psychotic patients.

serum factor is not only different from pyridoxal- $P$, but is also activating both enzymes in a manner independent of the presence of pyridoxal- $P$.

Thus, the factor present in the serum of these patients activates the above-mentioned serine-metabolizing enzymes resulting in lower concentrations of serine. This is reflected by lower serine concentrations in the fibroblasts. To cope with this decrease, serine will be taken up from the medium, which is in turn reflected by the lower serine concentrations in the medium (Table 2).

Activation of cystathionine $\beta$-synthase results in higher formation of taurine (Figure 1), which is in agreement with the higher concentrations of this amino acid found in the fibroblasts. Although it is attractive to speak of net taurine synthesis in the fibroblasts subcultured with patients' serum, facilitated transport cannot be excluded because this may result in only minor, and probably not detectable, alterations in the taurine concentration in the medium.

Activation of cystathionine $\beta$-synthase also results in lower production rates of methionine, because its precursor, homocysteine, will now be used for the increased synthesis of taurine. This is reflected by the lower methionine concentrations found in the fibroblasts. Subsequently, the uptake of methionine is increased, resulting in lower concentrations of this amino acid in the medium (Table 2). However, the uptake of methionine from the medium could not compensate for the decrease in the synthesis of this amino acid as the $P / N$ ratio of methionine in the fibroblasts $(0.89 \pm 0.02)$ is still lower than in the medium (0.94 \pm 0.02$)$.

A consequence of the activation of cystathionine $\beta$-synthase is not only a lesser availability of homocysteine for the synthesis of methionine, but this also may be responsible for an accumulation of 5-methyl- and 5,10-methylene tetrahydrofolic acid (Figure 1). Also, the activation of SHMT will contribute to an accumulation of 5,10-methylene tetrahydrofolic acid. This compound can, among others, dissociate into tetrahydrofolic acid and formaldehyde, of which the latter will condense with biogenic amines forming psychotogenic compounds like $\beta$-carbolines and isoquinolines, as has been postulated previously (Bruinvels et al 1980; Pepplinkhuizen et al 1980).

One could question the specificity of the serum factor to alter the activities of SHMT 
and cystathione $\beta$-synthase. Although it cannot be ruled out that this factor will activate other enzymes too, it is highly improbable that the serum factor nonspecifically alters any enzyme. Some evidence for the latter is given by the fact that the concentrations of all intracellular amino acids, except for serine, taurine, and methionine, are not influenced by this factor. A definite answer can only be given by measurement of enzymes that have nothing to do with serine, taurine, or methionine metabolism. However, the availability of cell material to periorm this control is a limiting factor.

In conclusion, the present study indicates that in the serum of a group of acute psychotic patients, one or more factors are responsible for the changes in the concentrations of serine, taurine, and methionine found in fibroblasts when subcultured with patients' serum. It remains for further study to identify the serum factor that may be responsible for the deranged one-carbon metabolism and for the psychedelic-psychotic episodes.

We thank Prof. M.F. Niermeijer, Ph.D., for the use of the facilities of the Department of Clinical Genetics and Mrs. J. Zaanen for typing the manuscript.

\section{References}

Bruinvels J, Pepplinkhuizen L (1984): Impaired glycine-serine conversion and increased plasma taurine levels in episodic psychotic patients with psychedelic symptoms. J Psychiatiy Res 18:307-318.

Bruinvels J, Pepplinkhuizen L (1985): Disturbances in serine-glycine metabolism in relation to acute psychoses with psychedelic symptoms. In Riederer P, Beckmann H (eds), Pathochemical Markers in Major Psychoses. Berlin: Springer Verlag, pp 59-73.

Bruinvels J, Pepplinkhuizen L, van Tuijl HR, Moleman P, Blom W (1980): Role of serine, glycine and the tetrahydrofolic acid cycle in schizo-affective psychosis. A hypothesis relating porphyrin biosynthesis and transmethylation. In Usdin E, Sourkes TL, Youdim MBH (eds), Enzymes and Neurutransmitters in Mental Disease. New York: John Wiley \& Sons, pp 139-154.

Diagno : and Statistical Manual of Mental Disorders, DSM-III-R, (ed 3) (1987). Am Psychiatric Association, Washington DC.

Fekkes D, Bruinvels J (1986): Serine and folate metabolism in fibroblasts from episodic psychotic patients with psychedelic symptoms. Biol Psychiatry 21:951-959.

Mudd SH, Uhlendorf BW, Hinds KR, Levy HL (1970): Deranged $B_{12}$ metabolism: Studies of fibroblasts grown in tissue culture. Biochem Med 4:215-239.

Pepplinkhuizen L, Bruinvels J, Blom W, Moleman P (1980): Schizophrenia-like psychosis caused by a metabolic disorder. Lancet 1:454-456. 